\title{
Socio-spatial Disparities and the Crisis: Swimming Pools as a Proxy of Class Segregation in Athens
}

\author{
Margherita Carlucci $^{1}$ (D) S Sabato Vinci ${ }^{2}$. Giuseppe Ricciardo Lamonica ${ }^{3}$. Luca Salvati ${ }^{4}$
}

Accepted: 17 July 2020 / Published online: 25 July 2020

(c) The Author(s) 2020

\begin{abstract}
Initially considered a 'luxury' good and now becoming a more popular and diffused landmark, the spatial distribution of residential swimming pools reflects the socio-spatial structure in Mediterranean cities, offering a kaleidoscopic overview of class segregation and economic disparities. The present study hypothesizes that economic downturns, resulting in alternative phases of social polarization and mixing, affect the spatial distribution of pools. To verify this assumption, the spatial distribution of pools in Athens, Greece- a city with evident social disparities and largely affected by the great recession-was analysed during the most recent expansion and recession. Results shed light on the spatial linkage between pool density, class segregation and dispersed urban expansion in a context of rising income disparities. The spatial distribution of swimming pools became increasingly polarized in the Athens' metropolitan region. The spread of residential pools in wealthier districts suggests how recession has consolidated disparities between rich and poor neighbourhoods. Based on the empirical findings of this study, pools can be considered a proxy of increased socio-spatial disparities reflecting class segregation and economic polarization at the local scale.
\end{abstract}

Keywords Urban-rural gradient · Economic structure $\cdot$ Urban management and governance $\cdot$ Indicators $\cdot$ Mediterranean city

Margherita Carlucci

margherita.carlucci@uniroma1.it

1 Department of Social and Economic Sciences, Sapienza University of Rome, Piazzale A. Moro 5, 00185 Rome, Italy

2 Department of Political Science, Third University of Rome, Via G. Chiabrera 199, 00145 Rome, Italy

3 Department of Social and Economic Sciences, Polytechnic University of Marche, Piazzale Martelli 8, 60121 Ancona, Italy

4 Department of Economics and Law, University of Macerata, Via Armaroli 43, 62100 Macerata, Italy 


\section{Introduction}

Urbanization forces reflecting complex socioeconomic processes at multiple spatial scales-from global to local-make investigation of the intrinsic linkage between metropolitan structures and social issues particularly challenging (Bruegmann 2005; Hall and Pain 2006; Angel et al. 2011; Li, Sun and Fang 2018). Urban growth has surely generated economic advantages and environmental costs, representing a challenge for sustainable land management, regional planning and social policies at large (Hasse and Lathrop 2003). In particular, specific forms of metropolitan growth-and, more specifically, urban sprawl - have consolidated social disparities and class segregation (Arapoglou and Sayas 2009; Janoschka and Arreortua 2017; Frenkel and Israel 2018).

In Mediterranean Europe, urban dynamics have determined peculiar social stratification and economic polarization in wealthier and disadvantaged districts (Chorianopoulos et al. 2010; Delladetsima 2012; Rontos et al. 2016), consolidating demographic divides and territorial disparities at both local and regional scales (Delladetsima 2006; Leontidou et al. 2007; Maloutas 2007). More specifically, urban growth has progressively altered Mediterranean landscapes toward a "lock-living" style (Munoz 2003), fuelling expansion of sparse settlements with homogeneous design, e.g. enclosed sites of detached houses with gardens and other amenities (Arapoglou and Sayas 2009; Pili et al. 2017; Ciommi et al. 2019). Being considered a traditional suburban architecture (Salvati et al. 2019), swimming pools are a key element of such landscapes (Sauri 2003; Domene et al.; 2005; Kallis 2010). In this perspective (private) swimming pools were often seen as a 'landmark of social disparities' (e.g. Kaika 2003; Domene and Sauri 2006; Cuadrado-Ciuraneta et al. 2017).

In countries where research findings support the validity of a positive relation between pool density and residents' income, like Greece (Zambon et al. 2017), the use of swimming pools as a proxy of social disparities in metropolitan regions opens new perspectives for empirical analysis. In fact, the (total or partial) lack of high-resolution statistical data assessing socioeconomic processes and contexts, in both emerging countries and some wealthy regions (e.g. Frenkel and Ashkenazi 2008), may prevent an in-depth analysis of social segregation at disaggregated spatial scales. Although a detailed evaluation of local contexts is crucial to understand patterns and processes of social segregation (Musterd et al. 2017), the most used statistical data are generally restricted to census-based variables, with critical issues related to untimeliness, spatial scale, varying classifications and definitions. On the contrary, pool mapping - easily performed using widely available and free tools (such as Google Earth)—produces comparable and disaggregated (i.e. point) information over time and space.

The above considerations lead to the first research question this paper will try to answer, i.e. to investigate the capability of (private) swimming pools to represent suburban landscapes reflected in low-density settlements and class segregation at the local scale, and influenced by socioeconomic disparities at regional scale. A detailed analysis of geo-referenced data on swimming pools in the Athens' metropolitan region (Greece) between the mid-2000s and the mid-2010s, was carried out to highlight the structure of their spatial distribution and density, in terms of spatial autocorrelation, concentration, connection with urban growth, so as to qualify the suitability of pools as a possible landmark of social inequalities. For the same purpose, a multivariate framework analysing a set of contextual variables related to socioeconomic and territorial attributes, was adopted to identify (apparent and latent) linkages between urban morphology, demo-economic structures and pool density. 
The second research question arises from assumptions on the role that alternate waves of economic expansion and recession play on urbanization patterns and class segregation. While in a positive economic climate, local development coupled with urban re-polarization and densification could sometimes re-balance spatially asymmetric and socially fragmented metropolitan structures, economic disparities under recession have more often consolidated sparse settlements and socially polarized neighbourhoods (Gkartzios 2013; Salvati 2016; Panori and Psycharis 2018; Panori et al. 2019). If social segregation was reflected in spatial patterns deviating significantly from a random distribution (Louf and Barthelemy 2016), newly built-up swimming pools should be distributed homogeneously over the study area during positive economic phases-consistently with the hypothesis of social homogenization. Based on this assumption, pools will be clustered in the most affluent locations with recession, as a sign of increasing socio-spatial disparities (Pacione 2003; Vidal et al. 2011; Zambon et al. 2018).

In this perspective, it was verified if the spatial distribution of swimming pools changes (e.g. becoming less or more concentrated) under economic expansion or recession, as a result of reduced (or increased) social disparities. For the empirical testing, it has been considered the increase in pool density at municipal scale separately for two time windows, respectively reflecting economic expansion (2005-2010) and recession (2010-2015) in Athens.

\subsection{Class Segregation and Socio-spatial Inequalities}

Socioeconomic conditions are intimated linked with urban morphology, with a predominant role played by social inequality, class segregation and economic polarization. The term 'polarization' has been originally introduced to indicate the empirical evidence of "disappearing middle class" in income distribution observed since the 1980s in the United States (Wolfson 1994). While no consensus has been reached on issues such as how to define middle class (Crankshaw 2017), or the choice of statistical measures to quantify shifts toward the tails (Foster and Wolfson 2010), the term has gained diffusion in regional economics (Gigliarano 2018).

Decreasing proportions of middle income families corresponded to a progressive shrinkage of middle-income neighborhoods (Booza et al. 2006). Thus, particularly relevant for this work is the notion of spatial polarization, in terms of "sharp divisions between urban and less urban, prosperous regions and less prosperous ones, regions with higher average levels of education and less, and those with less ethnic diversity and those with more" (Storper 2018; p. 248). Calling for the contemporary presence of high-skilled workers and low-skilled employees in services-as supposed in social transformations leading to "global" cities (Sassen 1991) - higher levels of polarization have been found in urban areas than in rural districts (Gornig and Goebel 2018). In metropolitan regions, social polarization had designed a spatial separation between wealthy suburban settlements and disadvantaged peripheral neighborhoods around compact cities (Yunda and Sletto 2020).

Urban transformations provide evidence that social inequalities could take the form of spatial segregation, i.e. separation of population groups over space. Due to the complex interplay of immigration flows, gentrification-driven displacement, diminishing social housing, on the one side, and the residential choices of high income groups, on the other side, spatial segregation has increased in North American and European cities (Piekut et al. 2019), assuming a variety of configurations: "the affluent and poor may be split not only between different neighborhoods, but concentrated over more or less land, more or less 
centralized, and clustered near or far from other similar neighborhoods" (Dwyer 2010, p. 114).

In Mediterranean cities, urban growth determined important consequences on spatial inequalities (Allen et al. 2004; Arbaci 2008; Arapoglou and Sayas 2009; Cassiers and Kesteloot 2012). In this region, the interplay between peculiar socio-demographic structures and a millenary urban tradition has reflected a stratification of compact and dispersed morphologies within metropolitan regions (Morelli et al. 2014). Between the 1960s and the 1980s, informal settlements - common to many Southern European cities-gave rise to a mostly deregulated and dense urban expansion (Chorianopoulos et al. 2010; Carlucci et al. 2017; Duvernoy et al. 2018). Since the 1980s, Southern European cities have undergone a rapid transition toward more dispersed morphologies (Schneider and Woodcock 2008), with distinctive patterns from both Northern and Western European cities and more similar traits with non-European Mediterranean cities (Gargiulo Morelli and Salvati 2014). Nevertheless, recent studies have demonstrated that each Mediterranean city presents unique settlement models and socioeconomic developments, especially as regard social issues of class segregation, neighbourhood fragmentation/isolation, and spatial entropy (Burgel 2004; Lamonica and Chelli 2018; Lichter et al. 2019).

\subsection{Pools as Landmark of Class Segregation}

Pools have been described as a ubiquitous amenity of detached houses with a garden, particularly frequent in low-density settlements (Salvati 2014; Cuadrado-Ciuraneta et al. 2017; Zambon et al. 2017). Thus, pools' suburban landscapes reflect new patterns of resource use associated with changing urbanization paths (Swyngedouw 2004; Vidal et al. 2011; Salvati et al. 2016). For instance, Vidal et al. (2011) hypothesized that changes in the spatial distribution of pools result in a growing polarization in the use of natural resources between metropolitan cores and suburbs. In other words, the presence of pools in suburban areas marks the difference between two typologies of scattered development: (1) sprawl as a result of an increasing demand for space and amenities of affluent households (Nechyba and Walsh 2004; Zambon et al. 2017; Guo et al. 2018), and (2) suburbanization of low social classes searching for affordable housing (Le Zhang and Pryce 2019; Piekut et al. 2019; Silver and Davidowski 2019).

Comparative and diachronic studies clarify the linkage between urban transformations, economic downturns, class segregation and sprawl, integrating pool indicators with ancillary official statistics evaluating socioeconomic transformations in contemporary metropolitan regions (Cuadrado-Ciuraneta et al. 2017; Pili et al. 2017; Duvernoy et al. 2018). From the operational point of view, an indicator based on pool spatial distribution may overcome the drawbacks of traditional census-based data used to measure segregation. Indexes of segregation, from the dissimilarity index to composite indicators of segregation's dimension (evenness, exposure, concentration, centralization, clustering, isolation, and their pairwise combination) or spatial distribution indexes (see, for instance, Massey and Denton 1988; Hogrebe and Tate 2019; Yao et al. 2019; Cruz-Sandoval et al. 2020; Najib 2020) are computed on data of population counts by race, number of children, education, income and other proxies of class segregation, e.g. socioeconomic vulnerability indexes (Martines et al. 2020). Census data are basically available at aggregated spatial scales (e.g. municipalities, urban districts, census tracks), being upgraded every 10 years and with 2-3 years needed for release and publication, as usual for census data (e.g. Durán and Condorí 2019). Moreover, census tracks are often unstable spatial units over time and the use of non-point, 
polygon-based geo-referenced data does not prevent statistical problems, such as the Modifiable Area Unit Problem, when calculating interpretative models based on exploratory multivariate statistics or regression approaches (Reardon et al. 2008). At the same time, although recording a comparatively homogeneous system of information-based on common definitions and nomenclature-census data may be less comparable across countries especially as far as classification of working systems is concerned, preventing an effective comparison among metropolitan regions (Coast et al. 2016; Fowler et al. 2016). By contrast, a better understanding of the increasingly complex spatial patterns of social segregation in contemporary cities requires comprehensive and comparative studies among metropolitan regions, using geo-referenced and high-resolution indicators over sufficiently long time intervals (Andersson et al. 2018; Anjoy et al. 2019; Nieuwenhuis et al. 2019). In this regard, pools data share the quality dimensions (relevance, accuracy, timeliness, accessibility, interpretability, and coherence) recommended by OECD (2008) for meaningful social indicators grounded on basic territorial information.

\subsection{Urban Growth and Socioeconomic Dynamics in Southern Europe: Athens as a Case Study}

The outward movement of higher and upper intermediate social groups to the Athens' outskirts has exacerbated spatial segregation, with the formation of relatively homogeneous middle-class suburbs (Maloutas and Spyrellis 2019). Spatial segregation was particularly evident between the wealthier neighbourhoods located in the Eastern part of the urban region and more disadvantaged districts in Western Attica (e.g. Arapoglou and Sayas 2009; Di Feliciantonio et al. 2018; Tammaru et al. 2019). Spatial segregation in downtown Athens was somewhat masked by the so-called vertical segregation (Maloutas and Karadimitriou 2001), with poorer households living in the lower floors of central buildings, and affluent ones living upside (Maloutas 2004, 2007, 2016). Changing spatial structures and the evolving local contexts in Athens were considered representative of the latent transition from compact-dense models to a more scattered configuration typical of contemporary cities in Southern Europe (De Rosa and Salvati 2016; Carlucci et al. 2017; Cuadrado-Ciuraneta et al. 2017; Zambon et al. 2018). At the same time, Athens is a consolidated example of socio-spatial patterns determined by past (radio-centric and partly deregulated) urban expansion (Arbaci 2008; Chorianopoulos et al. 2010, 2014; Di Feliciantonio and Salvati 2015; Maloutas 2016).

Since World War I, Athens' development was the result of massive refugee migration from Turkey and internal migration from rural areas during the Civil War (Leontidou 1990). Athens' economy experienced a rapid expansion in the 1950s, 1960s, and 1970s, shifting from an industrial-based production system to a tertiary-centered region, being increasingly oriented toward high value added services, e.g. finance, banking, insurance and real estate (Couch et al. 2007). Until the 1980s, urbanization involved municipalities around Athens and Piraeus, with some scattered hotspots along the coastal rim (Colantoni et al. 2016; Salvati and Serra 2016; Pili et al. 2017). Since the 1990s, urbanization accelerated in peripheral areas North-East and South-East of Athens, converting both cropland and forests to urban use (Morelli et al. 2014). The 2004 Olympic Games had a major impact on urban expansion, thanks to infrastructural investments and accelerated economic growth because of public spending and debt creation (Delladetsima 2006, 2012; Chorianopoulos et al. 2010, 2014). Finally, economic crisis exposed Attica to a prolonged phase of austerity urbanism (Di Feliciantonio et al. 2018). Unemployment, the increase of working 
poor and rising social disparities were relevant aspects of the Athens' growth in the last decade (Rontos et al. 2016; Salvati 2016; Panori et al. 2019). Thus, Athens was a unique case of controversial urban transformations spanning from the economic expansion following the 2004 Olympics to the catastrophic 2009 recession (Delladetsima 2006, 2012; Colantoni et al. 2016; Pili et al. 2017).

\section{Methodology}

\subsection{Study Area}

The investigated area $\left(3000 \mathrm{~km}^{2}\right)$ encompasses the mainland part of the Attica district corresponding to the historical and actual administrative region of Greece (NUTS-2 level of the European territorial statistics nomenclature). With its capital city, Athens, mainland Attica represents the core of the country and coincides with the Athens' metropolitan region according with the official definition provided by the Urban Atlas Land Copernicus initiative (European Environment Agency; for a detailed description of the study area see Zitti et al. 2015). The study area mostly consists of hilly districts and mountains bordering the flat area occupied by the Greater Athens' area (the so called 'Lekanopedio Attikis' in Greek). Climate regime in Attica is typically Mediterranean, with relatively hot and dry summers and mild winters. Maximum air temperature is systematically higher than $25^{\circ} \mathrm{C}$ from May to October and warm meteorological conditions can occur also during April and early November. All municipalities in the study area, including those belonging to the island of Salamina — close to Piraeus and Perama harbours — were considered in our study.

\subsection{Maps of Residential Swimming Pools}

Since official data on the spatial distribution of residential swimming pools are scarce and mostly unreliable, pools were diachronically mapped in the study area following the approach proposed by Vidal et al. (2011) and Zambon et al. (2017). Pools were enumerated at three different time points (mid-2000s, corresponding to a phase of economic expansion driven by 2004 Olympics; late-2000s/early 2010s, corresponding to the end of economic growth and the beginning of the great recession; mid-2010s, corresponding to late recession). An on-screen digitization of swimming pools was carried out on a wide set of high-resolution Google Earth imagery respectively dated 2004-2006, 2009-2011 and 2014-2016 (based on map availability in the different Attica districts) under supervision of an operator with wide knowledge of the study area. To achieve a homogeneous coverage of the study area in a time period when all swimming pools are used by residents, only images taken in summer months (June, July, August, and September) were evaluated. The centroid of each pool was specifically digitized to produce a digital point map. The mid-2000s pools' map constituted the base to create the late-2000s/early-2010s map. This map was, in turn, the base to realize the mid-2010s map. A spatial comparison between diachronic maps allowed identification of digitization errors and contributed to a more precise localization of pools over the entire study period (Salvati et al. 2016). To verify the reliability of Google Earth imagery as a source of information for pools' mapping, an independent map was derived from digitization of pools from ortho-photographs taken in the same time period (scaled 1:5000-1:10,000). The primary information source of this study was complemented with independent land-use maps with the aim to locate pools more precisely and 
to distinguish residential pools from other water surfaces. More specifically, a topographic map (1:5000) provided by the Hellenic Statistical Authority (ESYE) illustrating urban settlements in Attica and the Athens' Urban Atlas land-use map (scaled 1:10,000) were used to check (and eliminate from the data base when necessary) artificial water surfaces different from pools (e.g. urban ponds, ornamental fountains, agricultural ponds). It is worthwhile noting that the subject of interest here is surveying new-built swimming pools, not the houses associated with these pools. It is utterly possible that a house had been built up at a date $x$ and the related swimming pool only at a later $x+t$ date. However, since the construction of a swimming pool—be it built-up together with the house or built up lateralways means to have enough space in one's terrain and enough money to cover built-up and maintenance expenses (e.g. water, electricity, cleaning), this possibility does not affect the capability of pools to act as affluence landmarks (Salvati et al. 2016). A specific indicator of pool density (per $\mathrm{km}^{2}$ ) was calculated at the municipal scale for the three time points (2005, 2010, 2015); changes over time in pool density were also calculated at the same spatial scale for two time intervals (2005-2010 and 2010-2015).

\subsection{Local Context Indicators}

A total of 27 background indicators were calculated from official statistics (Table 1) with the aim at profiling the socioeconomic context of each municipality in the study area. A spatial partition of 115 municipalities and local communities (the former 'Kapodistrian' asset of local councils, more recently modified and reduced in number with the 'Kallikratis' law) was adopted in this study. Indicators were selected in accordance with other studies (Morelli et al. 2014; Colantoni et al. 2016; Rontos et al. 2016; Salvati and Serra 2016; Pili et al. 2017) with the objective to assess four basic dimensions of urban growth that include: (1) topography and territorial constraints (elevation, proximity to the sea coast, municipal surface area, distance from four urban centres-Athens, Piraeus, Maroussi, Markopoulo Messoghias), (2) settlement characteristics and demography (population density, population growth rate, buildings per inhabitant, residential settlements), (3) land-use (cropland, forests, protected areas), and (4) socioeconomic functions (average income level and growth over time, participation rate, working classes composition and diversification). It is worthy to note that the share of specific jobs in total workforce has proved to be a 'surprisingly effective' proxy for income (Williamson 2016, p. 463).

\subsection{Data Analysis}

Descriptive statistics of pool density (mean, standard error, minimum and maximum, as well as 25 th, 50th and 75th percentiles) were calculated with the aim at illustrating the spatial distribution of swimming pools by municipal unit and year. Pool density and cumulated distribution (\%) by district (Western Athens and Western Attica; Eastern Athens and Eastern Attica) were also calculated. A Lorenz curve was prepared with the aim at assessing inequalities in the spatial distribution of pools in the study area considering the cumulated distribution (per $\mathrm{km}^{2}$ ) by municipal unit at three points in time (2005, 2010 and 2015). A Gini inequality index was also calculated separately for the three time points. Thematic maps illustrating the spatial distribution of pools at the different time points were finally prepared. All these materials were considered preliminary to an exploratory analysis of changes in pool density based on (1) spatially explicit techniques (Moran's spatial autocorrelation coefficients), (2) non-parametric correlation coefficients with contextual variables 


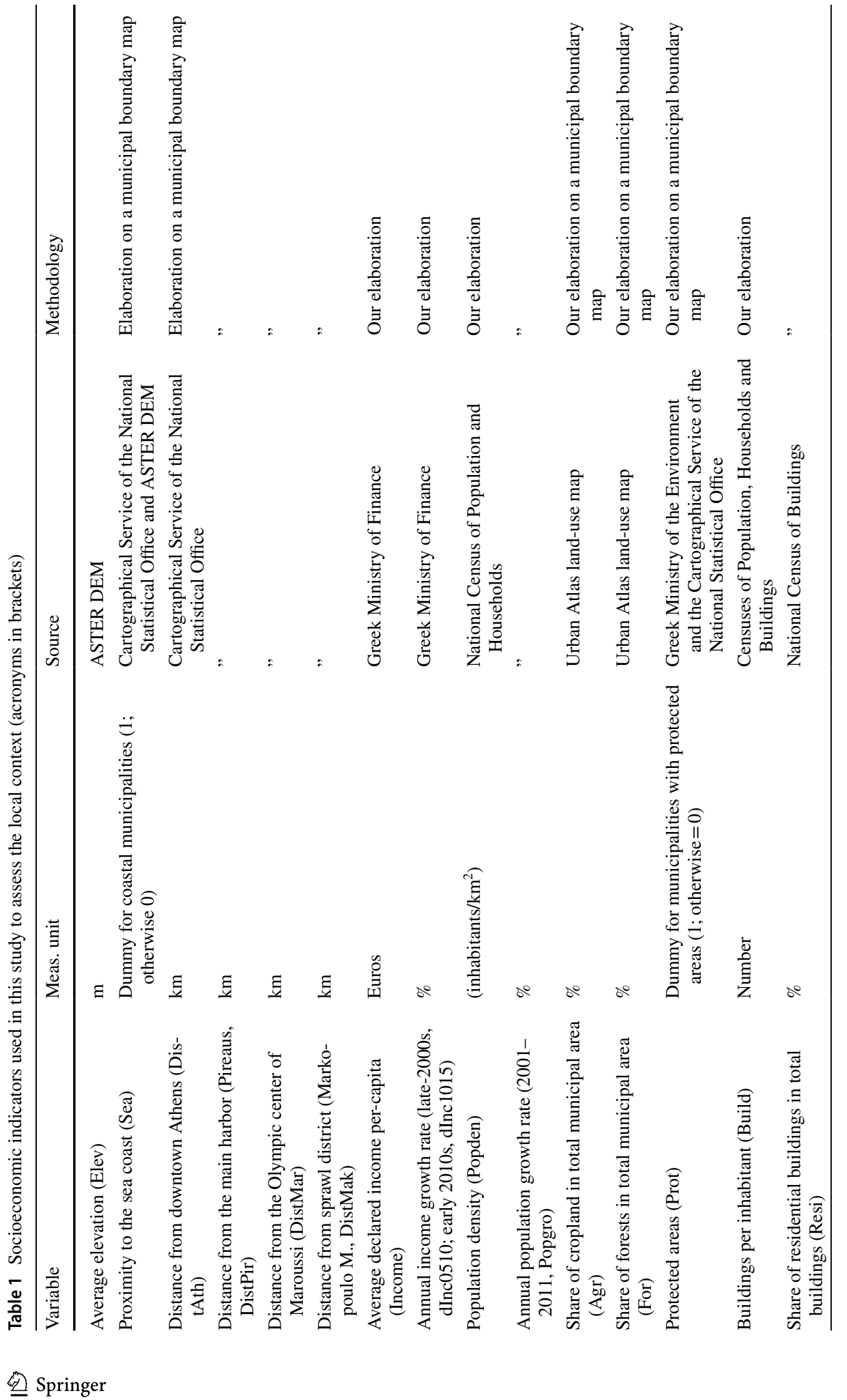




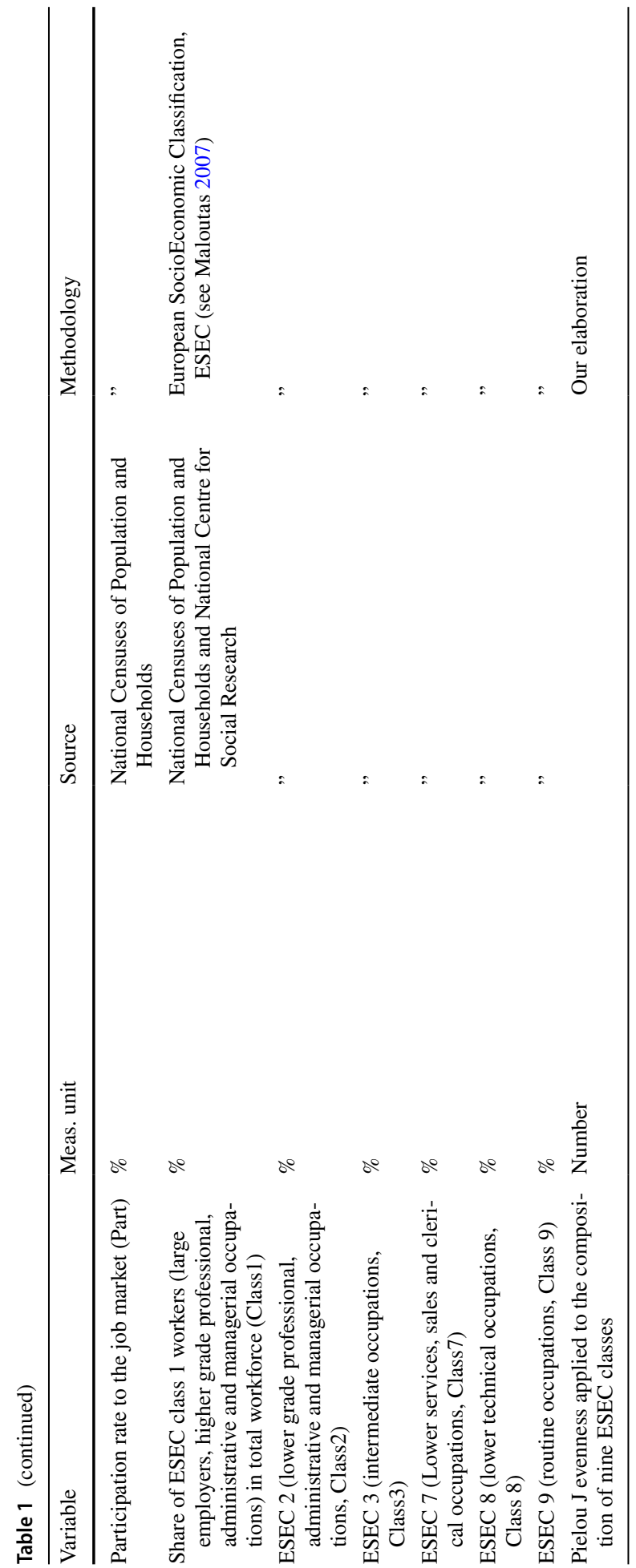


of urban growth (see above) and (3) a summary multivariate approach based on Principal Component Analysis (PCA). The goal of spatial analysis was to verify spatial randomness/ polarization in the distribution of pool density in the study area at different time points. The objective of correlation analysis was to identify the most important variables representing the linkage between the socioeconomic profile of each municipality and the spatial distribution of swimming pools at the beginning of the study period (as well as the differential increase in pool density during economic expansion and recession). Finally, a PCA was run to assess the existence (and the stability) of an intrinsic, latent relationship between key (territorial, settlement/demography, land-use, and socioeconomic) dimensions of urban change in the study area and pool density at the beginning and the end of the study period.

\subsection{Analysis of Spatial Autocorrelation}

Global measurements of spatial correlation provide a set of values that reflect the extent of spatial autocorrelation in a given variable across the study area (Salvati and Serra 2016). A global Moran's index of spatial autocorrelation was calculated on pool density at the beginning and the end of the study period at 8 bandwidths $(5,10,15,20,25,30,35$, and $40 \mathrm{~km}$ ) using Euclidean distance as the representative metric and municipal units as the elementary spatial domain. Multiple bandwidths were used to assess the intensity of spatial interactions in the selected variable moving from a local scale $(5 \mathrm{~km})$ to a regional scale $(40 \mathrm{~km})$. The same index and bandwidths were used to analyse the spatial structure of the per cent growth in pool density at two time intervals (2005-2010 and 2010-2015) considering the same spatial scale (municipal units). Coefficients of spatial autocorrelation were tested for significance at $p<0.001$. Significant coefficients indicate a (non-random) spatially asymmetric distribution of the studied variable; non-significant coefficients indicate a random distribution over space.

A local Moran's index of spatial autocorrelation was calculated on pool density at the same time points and municipal units with the aim at identifying spatial clusters and outliers. Maps of this index have been computed for two bandwidths (distinguishing localscale interactions, $5 \mathrm{~km}$, from regional-scale interactions, $40 \mathrm{~km}$ ), separately for each time point, testing for the null hypothesis of no local spatial association in pool density at $p<0.001$. Based on the local Moran's value at each unit, municipalities were classified as (1) High-High $(\mathrm{HH})$ hot spots (high values of the studied variable with similar neighbours), (2) Low-Low (LL) cold spots (low values with similar neighbours), (3) High-Low (HL) potential spatial outliers (high values with low-value neighbours), (4) Low-High (LH) potential spatial outliers (low values with high-value neighbours) and (5) units with no significant local autocorrelation.

\subsection{Non-parametric Correlations}

Non-parametric Spearman coefficients were used to correlate pair-wise (1) pool density in 2005 (or the rate of growth in pool density during (2) 2005-2010 and (3) 2010-2015) with the background variables (see above) assessing the socioeconomic profile of each municipality in the study area. Significant correlations were tested at $p<0.05$ after Bonferroni's correction for multiple comparisons (Munafò et al. 2013; Serra et al. 2014; Salvati and Serra 2016). Spearman correlation analysis delineated socioeconomic and territorial indicators having a significant (linear or non-linear) relationship with the distribution of 
swimming pools and the local-scale increase of pools during economic expansion and, respectively, recession.

\subsection{Principal Component Analysis}

A Principal Component Analysis (PCA) - a multivariate technique widely used to illustrate complex social systems (Gunderson and $\mathrm{Ng} 2006$ ) — was run on the correlation matrix derived from 29 variables (27 background indicators, pools' density and the rate of change over time: see list in Table 1) made available at 115 locations (all the municipalities in the study area). This analysis was aimed at identifying significant dimensions of urban expansion in Athens and the background factors associated with each component by exploring loadings (Colantoni et al. 2016; Pili et al. 2017; Duvernoy et al. 2018). By selecting principal components with eigenvalue $>1$, the analysis provides an indirect assessment of urbanization patterns and processes and the related socioeconomic forces in the study area. Taken as a supplementary variable, pool density at the beginning and the end of the study period (2005 and 2015) was correlated with the municipal scores of each component with the aim to verify the appropriateness of pool density as a proxy of socio-spatial inequalities over a sufficiently long time period (Zambon et al. 2017).

\section{Results}

\subsection{Descriptive Statistics}

The total number of residential swimming pools in the Athens' metropolitan region amounted to nearly 5300 pools in 2005, increasing by 6\% (per year) between 2005 and 2010 (2700 new pools and nearly 8000 pools in total) and 4\% between 2010 and 2015 (2100 new pools, nearly 10,100 pools in total). Pool density was taken as a representative indicator of the spatial distribution of this landmark at the municipal scale. The spatial distribution of pools was largely heterogeneous (Table 2), with an average density increasing from 4.3 pools $/ \mathrm{km}^{2}$ (2005) to 7.9 pools $/ \mathrm{km}^{2}$ (2015) and the absolute range (maximum-minimum density) rising from 75 pools $/ \mathrm{km}^{2}$ (2005) to 105 pools $/ \mathrm{km}^{2}$ (2015). The interquartile difference in pool density (75th-25th percentile) was 4 pools $/ \mathrm{km}^{2}(2005)$ and 7.2 pools $/ \mathrm{km}^{2}$ (2015). Figure 1 illustrates a Lorenz curve calculated considering the cumulated distribution of pools per $\mathrm{km}^{2}$ by municipality at three time points $(2005,2010$ and 2015). Pool distribution was found particularly concentrated in 2005 with nearly $50 \%$ and $10 \%$ of municipalities having respectively more than $95 \%$ and $70 \%$ of pools in the area. The curve indicates a less concentrated spatial distribution when referring to the new pools built-up between 2005 and 2010. Despite the high number of pools realized between 2010 and 2015, the spatial distribution of pools in this time window was again concentrated, as reflected in the Gini inequality index (2005: 0.80; 2005-2010: 0.76; 2010-2015: 0.79).

The highest density was observed in the Eastern part of the study area, with a traditionally more affluent population than the Western one. Particularly high densities were recorded in both Eastern Athens (urban area) and Eastern Attica (peri-urban area). These two districts concentrated nearly $97 \%$ of total swimming pools in the study area at both the beginning and the end of the study period. Figure 2 indicates a concentration of swimming pools in fringe municipalities Northeast and Southeast of Athens, and in sparse municipalities of Eastern Attica undergoing dispersed urban expansion. Conversely, a low pool 
Table 2 A descriptive analysis of the distribution of swimming pools in the study area by year

\begin{tabular}{lccc}
\hline Variable & 2005 & 2010 & 2015 \\
\hline Descriptive statistics & & & \\
Mean density & 4.27 & 6.43 & 7.88 \\
SE & 0.98 & 1.35 & 1.58 \\
Minimum & 0 & \multicolumn{1}{c}{0} & \multicolumn{1}{c}{0} \\
Maximum & 75.1 & 98.4 & 104.6 \\
Statistical distribution (pool density) & & & \\
25th percentile & 0.07 & 0.26 & 0.32 \\
Median & 0.84 & 1.55 & 2.11 \\
75th percentile & 4.07 & 5.60 & 7.48 \\
Pool density by prefecture & & & \\
Eastern Athens & 7.52 & 11.29 & 13.67 \\
Eastern Attica & 1.87 & 2.82 & 3.69 \\
Western Athens & 0.12 & 0.40 & 0.45 \\
Western Attica & 0.13 & 0.22 & 0.25 \\
Spatial distribution (\% pool share in & & & \\
$\quad$ total pools) by prefecture & & & \\
Eastern Athens & 41.87 & 41.38 & 39.70 \\
Eastern Attica & 54.95 & 54.78 & 56.79 \\
Western Athens & 0.33 & 0.72 & 0.66 \\
Western Attica & 2.84 & 3.11 & 2.86 \\
\hline
\end{tabular}

0.45

0.25

tern Attica

\section{.58}



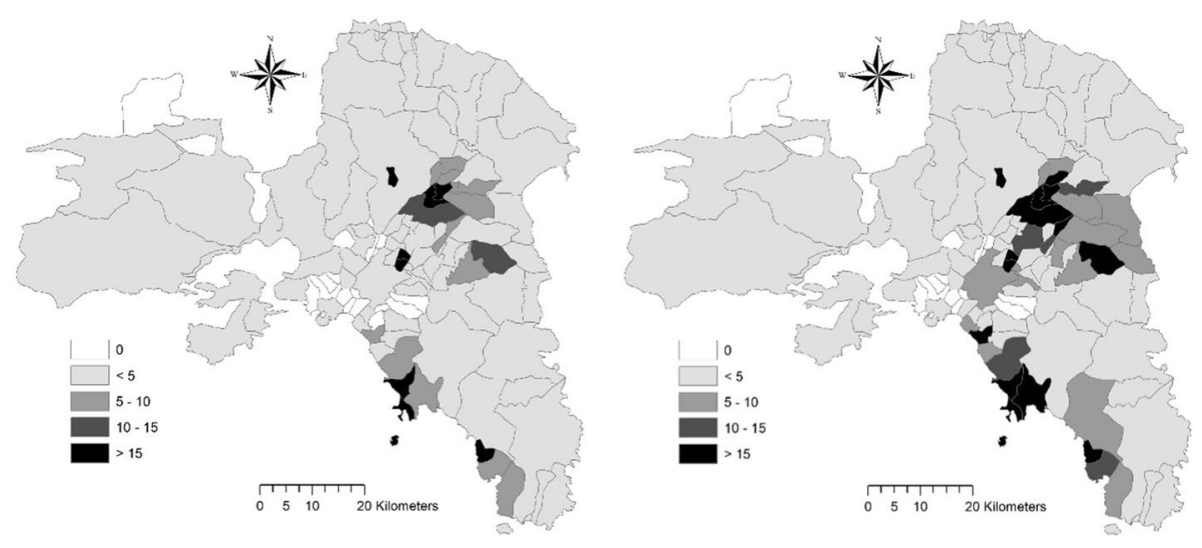

Fig. 2 Density of residential swimming pools (per $\mathrm{km}^{2}$ ) in the Athens' metropolitan region (2005: left; 2015: right)
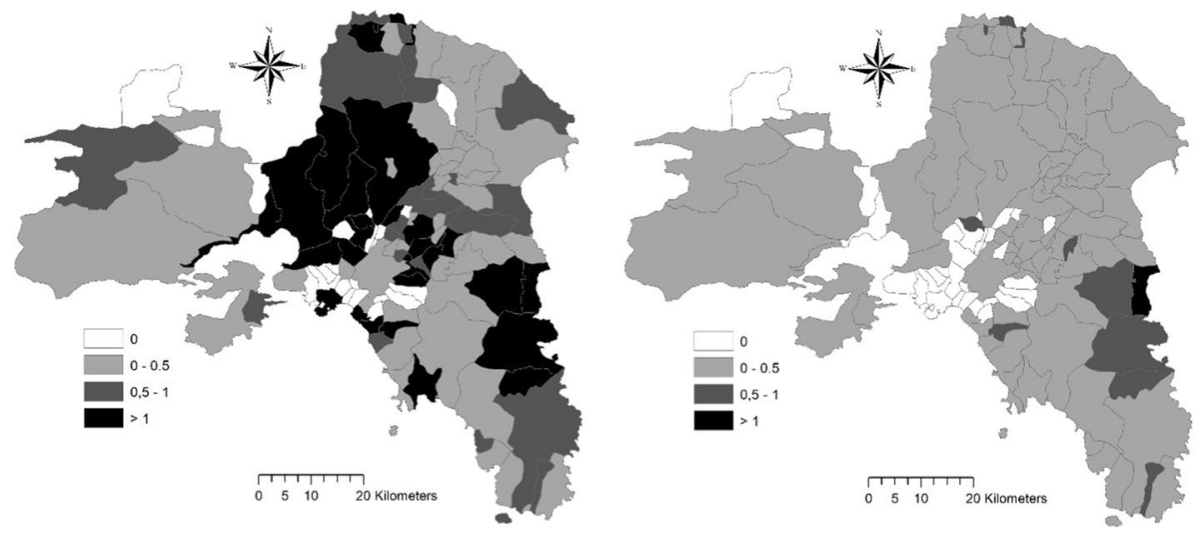

Fig. 3 Change over time (\%) in the density of residential swimming pools (per $\mathrm{km}^{2}$ ) in the Athens' metropolitan region (left: 2005-2010; right: 2010-2015)

faster increase in less affluent municipalities West and North of Athens during economic expansion (2005-2010) and an increased spatial concentration of pools in municipalities with an already medium-high pool density at the end of the study period, especially in Eastern Attica. These results may indicate a process of pool densification in areas with medium-high pool density, likely evidencing a moderate spillover in the surrounding districts (Table 2).

\subsection{Spatial Analysis}

The analysis of the global Moran's coefficient of spatial autocorrelation (Table 3) confirms a non-random spatial distribution of pools in Athens. The global Moran's $z$-scores were statistically significant for 2005 and 2015, indicating the persistence of a spatially asymmetric structure of pool density in the study area. Furthermore, $z$-scores for all bandwidths 
Table 3 Global Moran's spatial autocorrelation coefficients ( $z$-score) for pools' density by year

\begin{tabular}{|c|c|c|c|c|}
\hline \multirow[t]{2}{*}{$\begin{array}{l}\text { Bandwidth } \\
(\mathrm{km})\end{array}$} & \multicolumn{2}{|c|}{ Pool density } & \multicolumn{2}{|c|}{$\begin{array}{l}\text { Per cent growth in pool } \\
\text { density }\end{array}$} \\
\hline & 2005 & 2015 & 2005-2010 & 2010-2015 \\
\hline 5 & $4.50^{*}$ & $5.25^{*}$ & 0.78 & $4.74 *$ \\
\hline 10 & $4.43^{*}$ & $5.02 *$ & 0.75 & $8.48 *$ \\
\hline 15 & $4.95^{*}$ & $5.58 *$ & 1.28 & $9.19 *$ \\
\hline 20 & $4.68^{*}$ & $5.27 *$ & 0.83 & $9.80 *$ \\
\hline 25 & $4.18^{*}$ & $4.78^{*}$ & 1.06 & $9.73 *$ \\
\hline 30 & $4.27 *$ & $4.96 *$ & 0.85 & $9.32 *$ \\
\hline 35 & $4.52 *$ & $5.25^{*}$ & 0.79 & $8.94 *$ \\
\hline 40 & $4.75^{*}$ & $5.49 *$ & 0.89 & $8.81 *$ \\
\hline
\end{tabular}

*Significant coefficient at $p<0.001$

have increased over time, indicating a deepening divide in low-density and high-density municipalities. Non-randomness in the spatial distribution of (per cent) growth rate in pool density was also observed for new pools built up with recession, indicating spatial clustering at all bandwidths between 2010 and 2015. With economic expansion, the spatial structure of new pools built up between 2005 and 2010 was more homogeneous, since global Moran's coefficients were very low and non-significant at all bandwidths.

Considering both local-scale and regional-scale interactions, the spatial distribution of the local Moran's coefficient of spatial autocorrelation for pool density in Athens reflects hotspots with High-High $(\mathrm{HH})$ regime that include the most affluent municipalities Northeast of Athens (Kifissià, Maroussi, Psychikò, Filothei) and Southeast of Athens (Voula, Vouliagmeni, Vari), both remaining almost stable over time (Fig. 4). All these municipalities represent locations with very high pool densities and the highest per-capita declared income of the study area. Figure 5 illustrates the distribution of the local Moran's coefficients of spatial autocorrelation for the (per cent) growth rate of pools in 2005-2010 and 2010-2015. In the former period, a HH cluster was observed in less affluent municipalities North of Athens. In the latter period, a HH cluster was observed in peri-urban municipalities East of Athens mirroring a LL cluster in urban (less affluent) municipalities West of Athens (including Piraeus and surrounding locations). Cluster location was similar considering local- and regional-scale interactions. However, HH and LL clusters were a bit larger at higher bandwidths. Taken together, global and local Moran's indexes of spatial autocorrelation indicate a significant concentration of pools in medium-high density locations with affluent households especially East of Athens.

\subsection{Non-parametric Correlations}

A pair-wise Spearman correlation analysis was run to identify significant (linear and nonlinear) relationships between background variables and, separately, pool density at the beginning of the study period (2005) and the per cent rate of growth in pool density over time intervals reflecting economic expansion (2005-2010) and recession (2010-2015) in Athens (Table 4). Positive correlation coefficients for pool density were observed with percapita declared income, population growth rate, share of residential buildings in total building stock, share of the most affluent classes (ESEC1 and ESEC2) in total workforce and distance from the industrial area of Piraeus. Negative pair-wise correlations were observed 

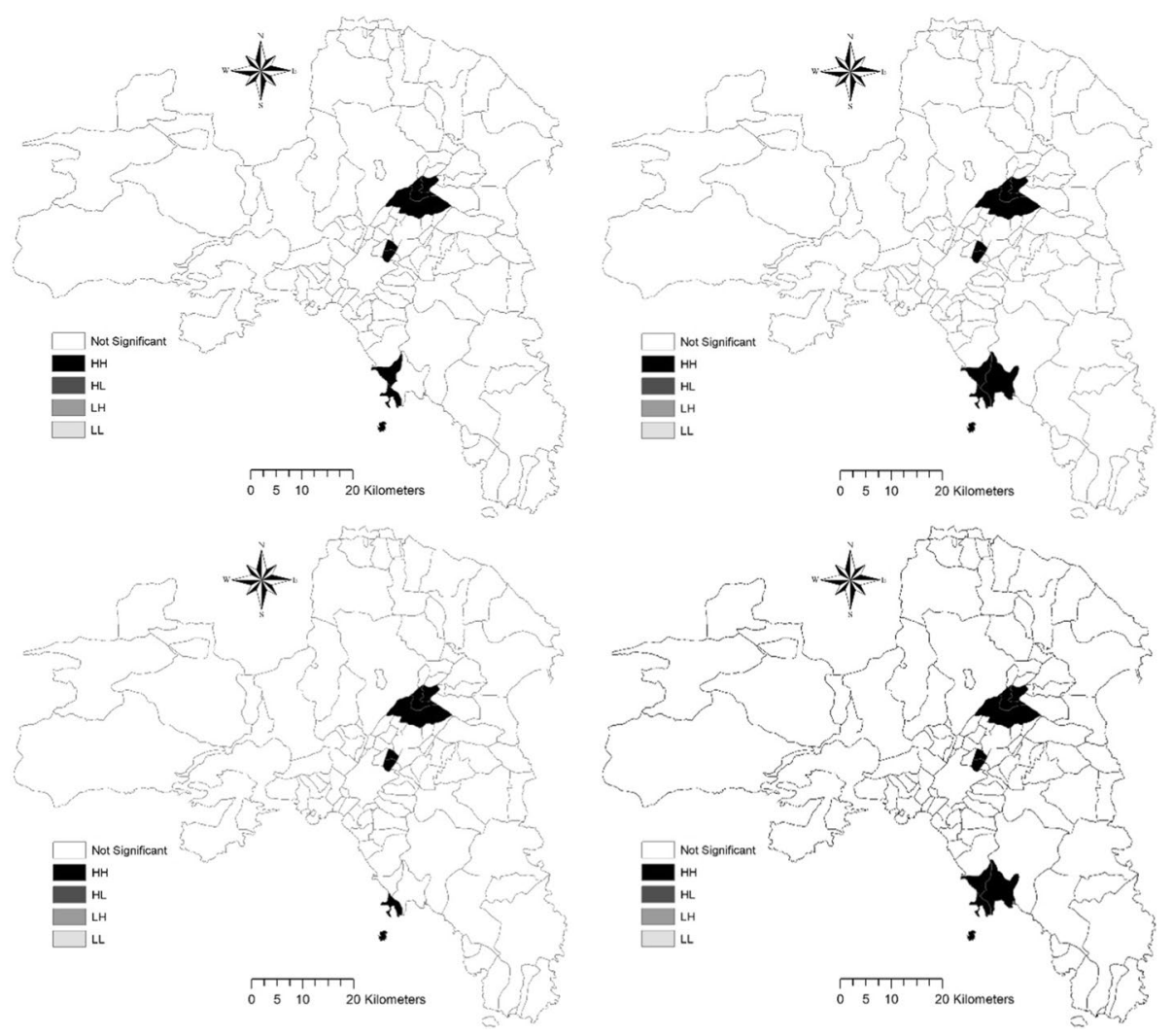

Fig. 4 Local Moran's spatial autocorrelation coefficients for pool density in the Athens' metropolitan region (upper line: $5 \mathrm{~km}$ bandwidth reflecting local scale interactions; lower line: $40 \mathrm{~km}$ bandwidth reflecting regional scale interactions; left: 2005; right: 2015); only municipalities with High-High ('HH') significant clusters were observed in the study area

between pool density and the proportion of less affluent working classes (ESEC 7, 8, 9), social evenness in working class composition (Pielou $\mathrm{J}$ ) and distance from the 'sprawled' district of Messoghia. With economic expansion, the rate of growth in pool density was significantly correlated with no background variables. With recession, the rate of growth in pool density increased significantly with the density of pools at the beginning of the time interval, the distance from downtown Athens and Piraeus, the rate of per-capita income growth and population growth, the share of cropland in total landscape and the share of residential buildings in total stock. A negative correlation was observed with population density, buildings per inhabitant and the share of ESEC 7 class in total workforce.

\subsection{Principal Component Analysis}

A multivariate exploratory analysis was developed to delineate the main latent dimensions at the base of recent processes of urban evolution in the study area, so as to correlate them with pool density at the beginning and the end of the study period (Table 5). Principal Component Analysis extracted four axes explaining about $67 \%$ of the total variance and identifying characteristic aspects of urban growth associated with specific contextual 

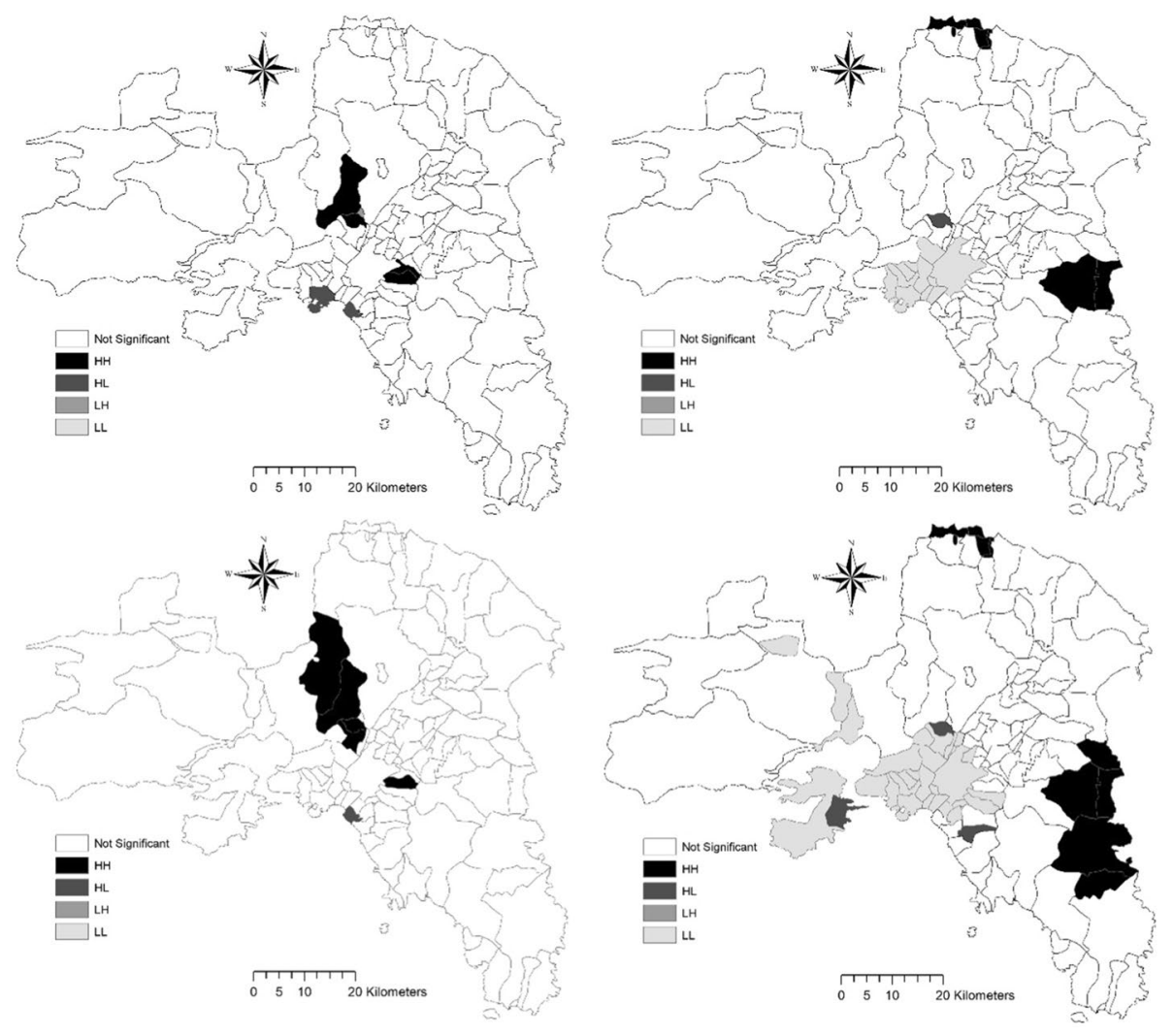

Fig. 5 Local Moran's spatial autocorrelation coefficients for per cent change in pool density over the Athens' metropolitan region (upper line: $5 \mathrm{~km}$ bandwidth reflecting local scale interactions; lower line: $40 \mathrm{~km}$ bandwidth reflecting regional scale interactions; left: 2005; right: 2015); acronyms indicate High-High ('HH'), High-Low ('HL'), Low-High ('LH') and Low-Low ('LL') significant clustering

indicators. Being associated negatively with population density, average per-capita income, buildings per inhabitant, participation rate and the upper three ESEC socioeconomic working classes, Component 1 (30\% of the total variance) identified the urban-rural gradient in Athens. Distances from the four urban centres (downtown Athens, Piraeus, Maroussi and Markopoulo Messoghias), share of cropland in total landscape, and the lower 2 ESEC socioeconomic classes correlated positively with Component 1 , identifying the variables most characteristic of compact/radio-centric urban expansion. Being positively correlated with the distance from Piraeus, per-capita declared income and income growth (or stability) during recession, share of residential buildings in total stock and share of the upper class ESEC 1, Component 2 (22\% of the total variance) identified a wealth gradient basically oriented from Eastern to Western Attica. Negative loadings were observed for population density, income growth during economic expansion, and the share of ESEC7 and ESEC8 classes in total workforce. Considering all components extracted, pool density at the beginning and the end of the study period were uniquely (and positively) correlated with Component 2, reflecting stability of the latent relationship between the spatial distribution of pools and social inequalities in Athens (Fig. 6). Components 3 and 4, which explain respectively $9 \%$ and $7 \%$ of the total variance, identified socioeconomic aspects with 
Table 4 Non-parametric Spearman rank correlation analysis by time interval (only significant coefficients at $p<0.05$ were shown after Bonferroni's correction for multiple comparison)*

\begin{tabular}{|c|c|c|c|}
\hline \multirow[t]{2}{*}{ Variables } & \multirow[t]{2}{*}{ Pool density, 2005} & \multicolumn{2}{|c|}{$\%$ Change in pool density } \\
\hline & & $2005-2010$ & $2010-2015$ \\
\hline Pools' density in the starting year & NA & & 0.43 \\
\hline Distance from Athens & & & 0.46 \\
\hline Distance from Piraeus & 0.35 & & 0.52 \\
\hline Distance from Markopoulo Mes. & -0.38 & & \\
\hline Average per-capita income & 0.69 & & \\
\hline Income growth rate & & & 0.30 \\
\hline Population density & & & -0.47 \\
\hline Population growth rate & 0.39 & & 0.40 \\
\hline Share of cropland in total landscape & & & 0.37 \\
\hline Buildings per inhabitant & & & -0.45 \\
\hline Share of res. buildings in total stock & 0.49 & & 0.43 \\
\hline Share of ESEC Class 1 in total workforce & 0.63 & & \\
\hline Class2 & 0.49 & & \\
\hline Class 7 & -0.49 & & -0.37 \\
\hline Class8 & -0.64 & & \\
\hline Class9 & -0.47 & & \\
\hline Pielou $\mathbf{J}$ eveness in working class composit & -0.32 & & \\
\hline
\end{tabular}

*Elevation, distance from Maroussi, proximity to the sea coast, share of forests in total landscape, protected areas, participation rate, share of ESEC working classes 3 in total workforce were non-significant at all dates (or time periods) investigated

less impact on the Athens' socio-spatial structure and completely unrelated with pool density. In particular, Component 3 represents the elevation gradient in Athens reflecting the asymmetric distribution of forests and protected areas across the region. This component identifies local contexts in marginal rural areas, mostly under environmental constraints. Component 4 reflects a gradient of social equality characteristic of municipalities with a high Pielou $\mathbf{J}$ evenness index in the composition of working classes and high population growth rates.

\section{Discussion}

Understanding the complex nexus between (changing) urban forms and socio-spatial processes is a deserving - albeit challenging — research issue (Di Feliciantonio and Salvati 2015; Maloutas 2018; Lawton 2019). Several factors (territorial, demographic, economic and political) have shaped the form and spatial organization of the Athens' metropolitan region (Couch et al. 2007; Arapoglou and Sayas 2009; Morelli et al. 2014). In particular, the interaction between different social classes has produced a spatial structure based on independent micro-entities and fragmented and heterogeneous "island" settlements characterized by class segregation at the local scale (Maloutas 2007; Kandylis et al. 2012; Panori et al. 2019) and a marked East-West divide at the regional scale (Leontidou 1996; Kourliouros 1997; Beriatos and Gospodini 2004; Salvati and Serra 2016). Recession has further 
Table 5 Component loadings (only coefficients $>|0.45|$ were shown)

\begin{tabular}{lcccc}
\hline Variable & Component 1 & Component 2 & Component 3 & Component 4 \\
\hline Proximity to the sea coast & & & -0.47 & \\
Average elevation & & & 0.57 & \\
Distance from Athens & 0.84 & & \\
Distance from Piraeus & 0.66 & 0.51 & \\
Distance from Maroussi & 0.81 & & \\
Distance from Markopoulo Mes. & 0.59 & & \\
Average per-capita income & -0.67 & 0.62 & \\
Income growth rate, 2005-2010 & & -0.50 & \\
Income growth rate, 2010-2015 & & 0.65 & \\
Population density & -0.63 & -0.59 & \\
Population growth rate & & & \\
Share of cropland in total landscape & 0.76 & & \\
Share of forests in total landscape & & & \\
Protected areas & & & \\
Buildings per inhabitant & -0.73 & & \\
Share of res. buildings in total stock & & 0.55 & \\
Participation rate & -0.57 & & \\
Share of ESEC Class 1 in total workforce & -0.66 & 0.68 & \\
$\quad$ Class2 & -0.78 & & \\
$\quad$ Class3 & -0.83 & & \\
Class7 & & & \\
Class8 & 0.61 & -0.61 & \\
Class9 & 0.71 & & \\
Pielou J eveness in working class composit. & & & \\
Pool density, 2005* & & & \\
Pool density, 2015* & & & \\
Explained variance (\%) & & & \\
\hline & & & \\
\end{tabular}

*Supplementary variables

enhanced class segregation (Salvati 2016; Hochstenbach and Musterd 2018; Panori and Psycharis 2018; Maloutas and Spyrellis 2019). The wealthier neighborhoods East of Athens have hosted an increasing share of high-income groups (Maloutas 2016; Di Feliciantonio et al. 2018; Tammaru et al. 2019), confirming a more general trend towards class segregation and gated communities among affluent citizens in contemporary European cities (Musterd 2005). Conversely, the most disadvantaged Western suburbs experienced worse residents' living conditions (Di Feliciantonio and Salvati 2015; Panori 2017; Kandylis et al. 2018).

The present study provides an alternative reading of social dynamics using swimming pools as a landmark for urban sprawl and territorial divides. In these regards, there is a urgent need for reliable, homogeneous and low-cost quantitative measurements of social disparities (Jaeger and Schwick 2014). Indicators of density and spatial distribution of pools can be used as a proxy of class segregation and social inequalities in specific local contexts and may corroborate traditional indicators (e.g. derived from 


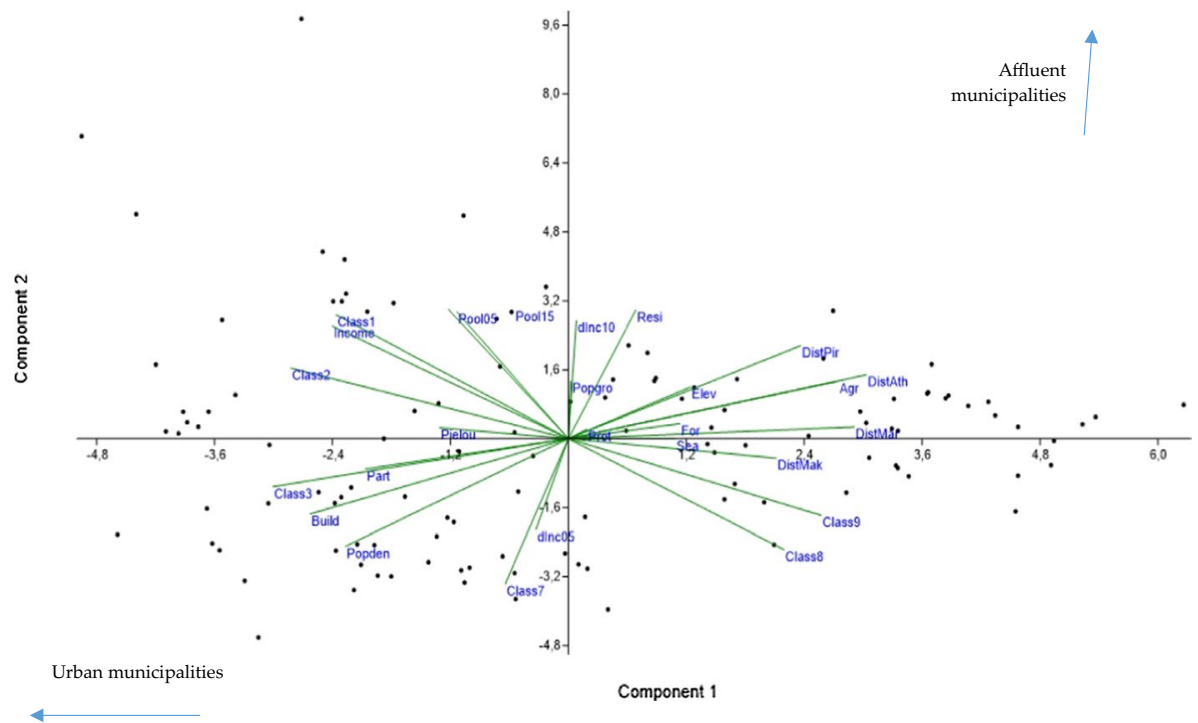

Fig. 6 Biplot of a Principal Component Analysis run on selected indicators of urban growth (see Table 1 for acronyms)

population censuses, official statistics and registers or sampling surveys) when geo-spatial data are lacking or have a partial temporal coverage.

Our results support the research hypothesis that the spatial distribution of swimming pools is a reliable indicator that allows interpretation of latent changes in the socio-spatial structure of urban areas, better characterizing territorial disparities in economically disadvantaged and "socially locked" Mediterranean contexts (Allen et al. 2004). Even with massive urban transformations driven by the 2004 Olympics (Beriatos and Gospodini 2004; Maloutas 2004; Di Feliciantonio and Salvati 2015), our analysis indicates how swimming pools have maintained an asymmetric spatial distribution in Attica. Considering together spatial autocorrelation, concentration and correlation with key urban dimensions, spatial distribution and density of pools highlight the spatial linkage between class segregation, low-density settlements, declared income and pool density.

Empirical results of this work also highlight some specificities of urban regions during economic expansion and recession. According to literature, Athens' geography suggests an interpretation of the latent mechanisms of urban growth based on stratification of different social forces in the metropolitan region (Couch et al. 2007). Recent economic downturns have highlighted new spatial polarizations, consolidating traditional segregation patterns. Economic expansion in the 2000s has stimulated infrastructural investments, resulting in low-density suburban expansion (Chorianopoulos et al. 2010, 2014). The subsequent recession had significantly impacted the Greek society. Unemployed (and working poor) in urban areas have progressively increased in Athens, exalting the traditional disparities in wealthy and disadvantaged neighbourhoods. The dichotomy between rich (East of Athens) and poor (West of Athens) districts was reflected in the metropolitan area, with the same gap observed in the surrounding rural areas. Despite a significant reduction of disposable income, worst socioeconomic conditions has markedly impacted poor and disadvantaged districts West of Athens, while Eastern districts demonstrated to be more resilient. 
Residential pools increased especially in neighbourhoods with higher pool density (hotspots) inhabited by skilled professionals, but this process was closely related to the residents' per-capita declared income only during recession. These results highlight how, with economic expansion, the demand for residential swimming pools characterized both highand medium-income peri-urban contexts while, with recession, demand for swimming pools was high only in wealthier contexts where crisis impacts less and incomes continue to increase or stabilize (Panori and Psycharis 2018). Thus, neighbourhoods with intermediate socioeconomic characteristics and moderate income decline (that have experienced an evident increase of swimming pools under economic expansion) showed no increases in pool density during recession. A trend towards spatial homogenization followed by repolarization patterns is confirmed by changes over time in the Gini index, known to be particularly sensitive to changes in the distribution of the variable of interest in the middle class (Braun 1988).

Our work definitely highlights how swimming pools were concentrated in a few areas, which coincide with the wealthiest municipalities in Athens. Social dynamics, both during economic expansion and the subsequent crisis, have further consolidated this spatial pattern. The resulting metropolitan context was characterized by strong social inequalities and an East-West divide that intensified with recession. A comparison with data provided by Vidal et al. (2011) for Barcelona indicates that regional disparities in the distribution of swimming pools are higher in Athens than in Barcelona, suggesting a greater importance of class segregation in the Greek capital. The spread of swimming pools towards the metropolitan region in Barcelona indicates a "popularization" of this luxury good and the progressive homologation of sprawled settlements (Domene and Sauri 2006). In Athens, pools continued playing the role of a typical luxury element of rich settlements, indicating divided urban landscapes and class segregation (Salvati et al. 2016). Such patterns confirm the uniqueness of development paths typical of the largest Mediterranean urban regions and claim for an in-depth comparative analysis of metropolitan systems as a contribution to sustainability and resilience of Southern European cities experiencing (more or less) rapid morphological changes.

\section{Conclusion}

The present study illustrates a feasible approach based on diachronic indicators to identify areas characterized by socio-spatial inequalities. Residential swimming pools proved to be a relevant landmark for peri-urban landscapes characterized by low- and medium-density settlements. Pool distribution in Athens highlights the polarization in wealthier and economically disadvantaged settlements suggesting that the proposed indicators can be effectively used to assess class segregation. Based on the procedure illustrated in this work, pool indicators endorse positive characteristics as a low-cost and comprehensive tool for monitoring social dynamics at both local and regional scales, since they can be easily derived from freely available sources comparable across countries and with global spatial coverage. A quantitative analysis confirms their reliability and coherency over time and the ability to discriminate between different spatial patterns. Further research should be devoted to a refined characterization of pool spatio-temporal distribution in terms of (multi)modality, outlining a more explicit linkage with other dimensions of urban expansion (e.g. spatial planning). 
The availability of trustworthy proxies of class segregation in urban settlements as tools for original approaches to Mediterranean urbanities is particularly needed at the end of a recession that has greatly impacted Southern European societies and the outcomes of which are still partially obscure. Providing an alternative reading of recent urban growth will contribute to a rethinking of the socioeconomic role of large Mediterranean cities-inbetween secularism and forces of globalization. In this respect, changes in socio-spatial structures towards a more effective cohesion will be one of the key issues to be further investigated in order to prepare for a post-crisis Mediterranean urbanity.

Acknowledgements Open access funding provided by Università degli Studi di Roma La Sapienza within the CRUI-CARE Agreement.

Open Access This article is licensed under a Creative Commons Attribution 4.0 International License, which permits use, sharing, adaptation, distribution and reproduction in any medium or format, as long as you give appropriate credit to the original author(s) and the source, provide a link to the Creative Commons licence, and indicate if changes were made. The images or other third party material in this article are included in the article's Creative Commons licence, unless indicated otherwise in a credit line to the material. If material is not included in the article's Creative Commons licence and your intended use is not permitted by statutory regulation or exceeds the permitted use, you will need to obtain permission directly from the copyright holder. To view a copy of this licence, visit http://creativecommons.org/licenses/by/4.0/.

\section{References}

Allen, J., Barlow, J., Leal, J., Maloutas, T., \& Padovan, L. (2004). Housing in southern Europe. London: Blackwell.

Andersson, E. K., Lyngstad, T. H., \& Sleutjes, B. (2018). Comparing patterns of segregation in North-Western Europe: A multiscalar approach. European Journal of Population, 34(2), 151-168.

Angel, S., Parent, J., Civco, D. L., Blei, A., \& Potere, D. (2011). The dimensions of global urban expansion: Estimates and projections for all countries, 2000-2050. Progress in Planning, 75(2), 53-107.

Anjoy, P., Chandra, H., \& Basak, P. (2019). Estimation of disaggregate-level poverty incidence in Odisha under area-level hierarchical Bayes small area model. Social Indicators Research, 144(1), 251-273.

Arapoglou, V. P., \& Sayas, J. (2009). New facets of urban segregation in southern Europe. European Urban and Regional Studies, 16(4), 345-362.

Arbaci, S. (2008). (Re)Viewing ethnic residential segregation in Southern European cities: Housing and urban regimes as mechanisms of marginalisation. Housing Studies, 23(4), 589-613.

Beriatos, E., \& Gospodini, A. (2004). "Glocalising" urban landscapes: Athens and the 2004 Olympics. Cities, 21(3), 187-202.

Booza, J., Cutsinger, J., \& Galster, G. (2006). Where did they go: the decline of middle-income neighborhoods in metropolitan America. Living cities census series. The Brookings Institution, Washington, DC.

Braun, D. (1988). Multiple measurements of US income inequality. The Review of Economics and Statistics, 70(3), 398-405.

Bruegmann, R. (2005). Sprawl: A compact history. Chicago: University of Chicago Press.

Burgel, G. (2004). Athènes, de la balkanisation à la mondialisation. Méditerranée, 103(3-4), 59-63.

Carlucci, M., Grigoriadis, E., Rontos, K., \& Salvati, L. (2017). Revisiting a hegemonic concept: Long-term 'Mediterranean urbanization' in between city repolarization and metropolitan decline. Applied Spatial Analysis and Policy, 10(3), 347-362.

Cassiers, T., \& Kesteloot, C. C. (2012). Socio-spatial inequalities and social cohesion in European cities. Urban Studies, 49(9), 1909-1924.

Chorianopoulos, I., Pagonis, T., Koukoulas, S., \& Drymoniti, S. (2010). Planning, competitiveness and sprawl in the Mediterranean city: The case of Athens. Cities, 27(4), 249-259.

Chorianopoulos, I., Tsilimigkas, G., Koukoulas, S., \& Balatsos, T. (2014). The shift to competitiveness and a new phase of sprawl in the Mediterranean city: Enterprises guiding growth in Messoghia, Athens. Cities, 39, 133-143. 
Ciommi, M., Chelli, F. M., \& Salvati, L. (2019). Integrating parametric and non-parametric multivariate analysis of urban growth and commuting patterns in a European metropolitan area. Quality \& Quantity, 53(2), 957-979.

Coast, E., Fanghanel, A., Lelièvre, E., \& Randall, S. (2016). Counting the population or describing society? A comparison of English and Welsh and French Censuses. European Journal of Population, 32(2), 165-188.

Colantoni, A., Grigoriadis, E., Sateriano, A., Venanzoni, G., \& Salvati, L. (2016). Cities as selective land predators? A lesson on urban growth, deregulated planning and sprawl containment. Science of the Total Environment, 545-546, 329-339.

Couch, C., Petschel-Held, G., \& Leontidou, L. (2007). Urban sprawl in Europe: Landscapes, land-use change and policy. Oxford: Blackwell.

Crankshaw, O. (2017). Social polarization in global cities: Measuring changes in earnings and occupational inequality. Regional Studies, 51(11), 1612-1621.

Cruz-Sandoval, M., Roca, E., \& Ortego, M. I. (2020). Compositional data analysis approach in the measurement of social-spatial segregation: Towards a sustainable and inclusive city. Sustainability. https://doi.org/10.3390/su12104293.

Cuadrado-Ciuraneta, S., Durà-Guimerà, A., \& Salvati, L. (2017). Not only tourism: Unravelling suburbanization, second-home expansion and "rural" sprawl in Catalonia, Spain. Urban Geography, 38(1), 66-89.

De Rosa, S., \& Salvati, L. (2016). Beyond a 'side street story'? Naples from spontaneous centrality to entropic polycentricism, towards a 'crisis city'. Cities, 51, 74-83.

Delladetsima, P. M. (2006). The emerging property development pattern in Greece and its impact on spatial development. European Urban and Regional Studies, 13(3), 245-278.

Delladetsima, P. M. (2012). Sustainable development and spatial planning: Some considerations arising from the Greek case. European Journal of Spatial Development, 46(1), 1-21.

Di Feliciantonio, C., \& Salvati, L. (2015). 'Southern' alternatives of urban diffusion: Investigating settlement characteristics and socio-economic patterns in three Mediterranean regions. Tijdschrift voor Economische en Sociale Geografie, 106(4), 453-470.

Di Feliciantonio, C., Salvati, L., Sarantakou, E., \& Rontos, K. (2018). Class diversification, economic growth and urban sprawl: Evidences from a pre-crisis European city. Quality \& Quantity, 52(4), 1501-1522.

Domene, E., \& Sauri, D. (2006). Urbanization and water consumption: Influential factors in the metropolitan region of Barcelona. Urban Studies, 43(9), 1605-1623.

Domene, E., Sauri, D., \& Parés, M. (2005). Urbanization and sustainable resource use: The case of garden watering in the metropolitan region of Barcelona. Urban Geography, 26(6), 520-535.

Durán, R. J., \& Condorí, M. Á. (2019). Deprivation index for small areas based on census data in Argentina. Social Indicators Research, 141(1), 331-363.

Duvernoy, I., Zambon, I., Sateriano, A., \& Salvati, L. (2018). Pictures from the other side of the fringe: Urban growth and peri-urban agriculture in a post-industrial city (Toulouse, France). Journal of Rural Studies, 57, 25-35.

Dwyer, R. E. (2010). Poverty, prosperity, and place: The shape of class segregation in the age of extremes. Social Problems, 57(1), 114-137.

Foster, J. E., \& Wolfson, M. C. (2010). Polarization and the decline of the middle class: Canada and the US. Journal of Economic Inequality, 8, 247-273.

Fowler, C. S., Rhubart, D. C., \& Jensen, L. (2016). Reassessing and revising commuting zones for 2010: History, assessment, and updates for US 'Labor-Sheds' 1990-2010. Population Research and Policy Review, 35(2), 263-286.

Frenkel, A., \& Ashkenazi, M. (2008). Measuring urban sprawl: How can we deal with it? Environment and Planning B: Planning and Design, 35(1), 56-79.

Frenkel, A., \& Israel, M. J. (2018). Spatial inequality in the context of city-suburb cleavages: Enlarging the framework of well-being and social inequality. Landscape and Urban Planning, 177, 328-339.

Gargiulo Morelli, V., \& Salvati, L. (2014). Unveiling urban sprawl in the Mediterranean region: Towards a latent urban transformation? International Journal of Urban and Regional Research, 38(6), 1935-1953.

Gigliarano, C. (2018). Income and social polarization: Empirical findings. In C. D’Ambrosio (Ed.), Handbook of research on economic and social well-being (pp. 460-479). Cheltenham: Edward Elgar Publishing.

Gkartzios, M. (2013). 'Leaving Athens': Narratives of counterurbanisation in times of crisis. Journal of Rural Studies, 32, 158-167. 
Gornig, M., \& Goebel, J. (2018). Deindustrialisation and the polarisation of household incomes: The example of urban agglomerations in Germany. Urban Studies, 55(4), 790-806.

Gunderson, R. J., \& Ng, P. T. (2006). Summarizing the effect of a wide array of amenity measures into simple components. Social Indicators Research, 79(2), 313-335.

Guo, Y., Chang, S. S., Chen, M., \& Yip, P. S. F. (2018). Do poorer areas have poorer access to services in Hong Kong? A small-area analysis based on multiple spatial accessibility indicators. Social Indicators Research, 138(1), 1-21.

Hall, P. G., \& Pain, K. (2006). The polycentric metropolis. Learning from mega-city regions in Europe. London: Earthscan.

Hasse, J. A., \& Lathrop, R. G. (2003). Land resource impact indicators of urban sprawl. Applied Geography, 23(2-3), 159-175.

Hochstenbach, C., \& Musterd, S. (2018). Gentrification and the suburbanization of poverty: Changing urban geographies through boom and bust periods. Urban Geography, 39(1), 26-53.

Hogrebe, M. C., \& Tate, W. F. (2019). Residential segregation across Metro St. Louis school districts: Examining the intersection of two spatial dimensions. AERA Open, 5(1), 1-13.

Jaeger, J. A. G., \& Schwick, C. (2014). Improving the measurement of urban sprawl: Weighted Urban Proliferation (WUP) and its application to Switzerland. Ecological Indicators, 38, 294-308.

Janoschka, M., \& Arreortua, L. S. (2017). Peripheral urbanisation in Mexico City. A comparative analysis of uneven social and material geographies in low-income housing estates. Habitat International, 70, 43-49.

Kaika, M. (2003). Constructing scarcity and sensationalising water politics: 170 days that shook Athens. Antipode, 35(5), 919-954.

Kallis, G. (2010). Coevolution in water resource development. The vicious cycle of water supply and demand in Athens, Greece. Ecological Economics, 69(4), 796-809.

Kandylis, G., Maloutas, T., \& Myofa, N. (2018). Exceptional social housing in a residual welfare state: Housing estates in Athens, Greece. In D. B. Hess, T. Tammaru, \& M. vanHam (Eds.), Housing estates in Europe. Poverty, ethnic segregation and policy challenges (pp. 77-98). Cham: Springer Open.

Kandylis, G., Maloutas, T., \& Sayas, J. (2012). Immigration, inequality and diversity: Socio-ethnic hierarchy and spatial organization in Athens, Greece. European Urban and Regional Studies, 19(3), 267-286.

Kourliouros, E. (1997). Planning industrial location in Greater Athens: The interaction between deindustrialization and anti-industrialism during the 1980s. European Planning Studies, 5(4), 435-460.

Lamonica, G. R., \& Chelli, F. M. (2018). The performance of non-survey techniques for constructing subterritorial input-output tables. Papers in Regional Science, 97(4), 1169-1202.

Lawton, P. (2019). Unbounding gentrification theory: Multidimensional space, networks and relational approaches. Regional Studies. https://doi.org/10.1080/00343404.2019.1646902.

Le Zhang, M., \& Pryce, G. (2019). The dynamics of poverty, employment and access to amenities in polycentric cities: Measuring the decentralisation of poverty and its impacts in England and Wales. Urban Studies. https://doi.org/10.1177/0042098019860776.

Leontidou, L. (1990). The Mediterranean city in transition. Cambridge: Cambridge University Press.

Leontidou, L. (1996). Alternatives to modernism in (Southern) urban theory: Exploring in-between spaces. International Journal of Urban and Regional Research, 20(2), 180-197.

Leontidou, L., Afouxenidis, A., Kourliouros, E., \& Marmaras, E. (2007). Infrastructure-related urban sprawl: Mega-events and hybrid peri-urban landscapes in southern Europe. In C. Couch, G. PetschelHeld, \& L. Leontidou (Eds.), Urban sprawl in Europe: Landscapes, land-use change and policy (pp. 71-101). Oxford: Blackwell.

Li, G., Sun, S., \& Fang, C. (2018). The varying driving forces of urban expansion in China: Insights from a spatial-temporal analysis. Landscape and Urban Planning, 174, 63-77.

Lichter, D., Parisi, D., \& Ambinakudige, S. (2019). The spatial integration of immigrants in Europe: A cross-national study. Population Research and Policy Review. https://doi.org/10.1007/s11113-01909540-3.

Louf, R., \& Barthelemy, M. (2016). Patterns of residential segregation. PLoS ONE. https://doi.org/10.1371/ journal.pone.0157476.

Maloutas, T. (2004). Segregation and residential mobility. Socially entrapped social mobility and its impact on segregation in Athens. European Urban and Regional Studies, 11(3), 195-211.

Maloutas, T. (2007). Socio-economic classification models and contextual difference: The "European socioeconomic classes" (ESeC) from a South European angle. South European Society and Politics, 12(4), $443-460$.

Maloutas, T. (2016). Socioeconomic segregation in Athens at the beginning of the 21st Century. In T. Tammaru, S. Marcińczak, M. van Ham, \& S. Musterd (Eds.), European capital cities: East meets West (pp. 1022-1024). London: Routledge. 
Maloutas, T. (2018). Travelling concepts and universal particularisms: A reappraisal of gentrification's global reach. European Urban and Regional Studies, 25(3), 250-265.

Maloutas, T., \& Karadimitriou, N. (2001). Vertical social differentiation in Athens: Alternative or complement to community segregation? International Journal of Urban and Regional Research, 25(4), 699-716.

Maloutas, T., \& Spyrellis, S. N. (2019). Segregation trends in Athens: The changing residential distribution of occupational categories during the 2000s. Regional Studies. https://doi.org/10.1080/00343 404.2018.1556392.

Martines, M. R., Cavagis, A. D. M., Kawakubo, F. S., Morato, R. G., Ferreira, R. V., \& Toppa, R. H. (2020). Spatial segregation in floodplain: An approach to correlate physical and human dimensions for urban planning. Cities. https://doi.org/10.1016/j.cities.2019.102551.

Massey, D. S., \& Denton, N. A. (1988). The dimensions of residential segregation. Social Forces, 67(2), 281-315.

Morelli, V., Rontos, K., \& Salvati, L. (2014). Between suburbanisation and re-urbanisation: Revisiting the urban life cycle in a Mediterranean compact city. Urban Research \& Practice, 7(1), 74-88.

Munafò, M., Salvati, L., \& Zitti, M. (2013). Estimating soil sealing rate at national level-Italy as a case study. Ecological Indicators, 26, 137-140.

Munoz, F. (2003). Lock living: Urban sprawl in Mediterranean cities. Cities, 20(6), 381-385.

Musterd, S. (2005). Social and ethnic segregation in Europe: Levels, causes, and effects. Journal of Urban Affairs, 27(3), 331-348.

Musterd, S., Marcińczak, S., van Ham, M., \& Tammaru, T. (2017). Socioeconomic segregation in European capital cities Increasing separation between poor and rich. Urban Geography, 38(7), $1062-1083$

Najib, K. (2020). Socio-spatial inequalities and dynamics of rich and poor enclaves in three French cities: A policy of social mixing under test. Population Space Place. https://doi.org/10.1002/ psp. 2280 .

Nechyba, T. J., \& Walsh, R. P. (2004). Urban sprawl. Journal of Economic Perspectives, 18(4), 177-200.

Nieuwenhuis, J., Tammaru, T., van Ham, M., Hedman, L., \& Manley, D. (2019). Does segregation reduce socio-spatial mobility? Evidence from four European countries with different inequality and segregation contexts. Urban Studies. https://doi.org/10.1177/0042098018807628.

OECD. (2008). Handbook on constructing composite indicators. Methodology and user guide. Paris: OECD Publications.

Pacione, M. (2003). Urban environmental quality and human wellbeing: A social geographical perspective. Landscape and Urban Planning, 65(1-2), 19-30.

Panori, A. (2017). A tale of hidden cities. The Region, 4(3), 19-38.

Panori, A., \& Psycharis, Y. (2018). The impact of the economic crisis on poverty and welfare in Athens. Region et Developpement, 48, 23-40.

Panori, A., Psycharis, Y., \& Ballas, D. (2019). Spatial segregation and migration in the city of Athens: Investigating the evolution of urban socio-spatial immigrant structures. Population, Space and Place, 25(5), e2209.

Piekut, A., Pryce, G., \& van Gent, W. (2019). Segregation in the Twenty First century: Processes, complexities and future directions. Tijdschrift voor Economische en Sociale Geografie, 110(3), 225-234.

Pili, S., Grigoriadis, E., Carlucci, M., Clemente, M., \& Salvati, L. (2017). Towards sustainable growth? A multi-criteria assessment of (changing) urban forms. Ecological Indicators, 76, 71-80.

Reardon, S. F., Matthews, S. A., O’Sullivan, D., Lee, B. A., Firebaugh, G., Farrell, C. R., et al. (2008). The geographic scale of metropolitan racial segregation. Demography, 45(3), 489-514.

Rontos, K., Grigoriadis, E., Sateriano, A., Syrmali, M., Vavouras, I., \& Salvati, L. (2016). Lost in protest, found in segregation: Divided cities in the light of the 2015 "O $\chi \mathrm{l}$ " referendum in Greece. City, Culture and Society, 7(3), 139-148.

Salvati, L. (2014). Agro-forest landscape and the 'fringe' city: A multivariate assessment of land-use changes in a sprawling region and implications for planning. Science of the Total Environment, 490, 715-723.

Salvati, L. (2016). The dark side of the crisis: Disparities in per Capita income (2000-12) and the UrbanRural Gradient in Greece. Tijdschrift voor Economische en Sociale Geografie, 107(5), 628-641.

Salvati, L., Ciommi, M. T., Serra, P., \& Chelli, F. M. (2019). Exploring the spatial structure of housing prices under economic expansion and stagnation: The role of socio-demographic factors in metropolitan Rome, Italy. Land Use Policy, 81, 143-152.

Salvati, L., Ridolfi, E., Sauri, D., \& Serra, P. (2016). Latent sprawl, divided Mediterranean landscapes: Urban growth, swimming pools, and the sociospatial structure of Athens, Greece. Urban Geography, 37(2), 296-312. 
Salvati, L., \& Serra, P. (2016). Estimating rapidity of change in complex urban systems: A multidimensional, local-scale approach. Geographical Analysis, 48(2), 132-156.

Sauri, D. (2003). Lights and shadows of urban water demand management. The case of the metropolitan region of Barcelona. European Planning Studies, 11(3), 229-243.

Schneider, A., \& Woodcock, C. E. (2008). Compact, dispersed, fragmented, extensive? A comparison of urban growth in twenty-five global cities using remotely sensed data, pattern metrics and census information. Urban Studies, 45(3), 659-692.

Serra, P., Vera, A., Tulla, A. F., \& Salvati, L. (2014). Beyond urban-rural dichotomy: Exploring socioeconomic and land-use processes of change in Spain (1991-2011). Applied Geography, 55, 71-81.

Silver, H., \& Davidowski, L. (2019). Fighting housing discrimination in Europe. Housing Policy Debate, 29(5), 714-735.

Storper, M. (2018). Separate Worlds? Explaining the current wave of regional economic polarization. Journal of Economic Geography, 18, 247-270.

Swyngedouw, E. (2004). Social power and the urbanization of water. Oxford: Oxford University Press.

Tammaru, T., Marcinczak, S., Aunap, R., vanHam, M., \& Janssen, H. (2019). Relationship between income inequality and residential segregation of socioeconomic groups. Regional Studies. https://oi. org/10.1080/00343404.2018.1540035.

Vidal, M., Domene, E., \& Sauri, D. (2011). Changing geographies of water-related consumption: Residential swimming pools in suburban Barcelona. Area, 43(1), 67-75.

Williamson, P. (2016). Small-Area incomes: Their spatial variability and the relative efficacy of proxy, geodemographic, imputed and model-based estimates. Applied Spatial Analysis and Policy, 9(4), 463-489.

Wolfson, M. C. (1994). When inequalities diverge. The American Economic Review, 84(2), 353-358.

Yao, J., Wong, D. W. S., Bailey, N., \& Minton, J. (2019). Spatial segregation measures: A methodological review. Tijdschrift voor Economische en Sociale Geografie, 110(3), 235-250.

Yunda, J. G., \& Sletto, B. (2020). Densification, private sector-led development, and social polarization in the global south: Lessons from a century of zoning in Bogotá. Cities. https://doi.org/10.1016/j.citie s.2019.102550.

Zambon, I., Benedetti, A., Ferrara, C., \& Salvati, L. (2018). Soil matters? A multivariate analysis of socioeconomic constraints to urban expansion in Mediterranean Europe. Ecological Economics, 146, 173-183.

Zambon, I., Serra, P., Sauri, D., Carlucci, M., \& Salvati, L. (2017). Beyond the 'Mediterranean City': Socioeconomic disparities and urban sprawl in three southern European cities. Geografiska Annaler: Series B, Human Geography, 99(3), 319-337.

Zitti, M., Ferrara, C., Perini, L., Carlucci, M., \& Salvati, L. (2015). Long-term urban growth and land use efficiency in Southern Europe: Implications for sustainable land management. Sustainability, 7(3), 3359-3385.

Publisher's Note Springer Nature remains neutral with regard to jurisdictional claims in published maps and institutional affiliations. 